\title{
Petrophysical parameters of the porous space of the "tight" type sandstones of the Skole Unit - Preliminary analysis
}

\author{
Michat Maruta ${ }^{1, *}$, and Vitalij Kułynycz ${ }^{1}$ \\ ${ }^{1}$ AGH University of Science and Technology, Faculty of Drilling, Oil and Gas, 30 Mickiewicza Av., \\ 30-059 Krakow, Poland
}

\begin{abstract}
The scientific goal of the paper is the physical characteristics of pore space of the Inocereamian Sandstones located in the Skole Unit as a part of the Outer Carpathians - The Carpathian Flysch. Rock samples were tested using mercury porosimeter. Using this method, cumulative curves of effective porosity were obtained, as well as the pore geometry distribution and pore surface area distribution. geometry and distribution. In the article the authors determine the physical parameters of the pore space for 30 samples, such as porosity, permeability, size and distribution of pore diameter, specific surface area and geometry of a pore space. Preliminary analysis of rock samples is to answer the question of the existence of sandstones capable of forming "tight" type deposits of natural gas and determining their reservoir parameters.
\end{abstract}

\section{Introduction}

The "tight" type deposits are formed by the accumulation of hydrocarbons in reservoir rocks with very poor filtration parameters. These types of deposits can achieve high porosities. On the other hand, the microporous development of the parameters of the pore space gives a permeability less than $0.1 \mathrm{mD}$. This microporous development is the only factor that distinguishes the "tight" deposit from conventional deposits [1].

Porosity, permeability and pore space parameters analysis are extremely important for gas and oil-bearing rocks, allowing the estimation of accumulated hydrocarbons in the rock, while properly measured parameters of the pore space formation also assess the gas or oil production of a rock formation [1,2].

In this study the application of the mercury porosimetry technique in determination of different reservoir parameters have been investigated. Mercury injection capillary pressure (MICP) data have been widely used to characterize reservoir rocks, evaluating sealing capacity for traps and to explain the locations of hydrocarbon accumulations and transition zones. This method can determine a broader pore size distribution more quickly and accurately than other methods. It can be used to characterize pores ranging from $0.003 \mu \mathrm{m}$ to $360 \mu \mathrm{m}$ using a single theoretical model. The data produced (mercury intrusion volume

\footnotetext{
Corresponding author: maruta@agh.edu.pl
} 
at various pressures) can be used to calculate numerous sample characteristics such as pore size distributions, total pore volume, total pore surface area, median pore diameter, and sample densities (bulk and skeletal) [3].

\section{Materials and methods}

\subsection{Geological background}

From the geological point of view the Polish part of the Outer Carpathians is built from many nappes, folds and scales overthrusted overthrown usually in the North direction. These formations were deposited in the presence of turbidity currents with a variable density in a deep-sea environment. Alternately lay shoals of conglomerates, sandstones, siltstones and claystones formed geological layers called the Flysch [4, 5].

The study area is located within the Skole unit (Fig. 1), which stretches from the Romanian Carpathians through the cities of Skole and around Przemyśl, Rzeszów to Bochnia, where fading hidden under the Silesian unit. The width of the belt on the eastern edge of the unit is $40 \mathrm{~km}$ and narrows toward the west [4-6].

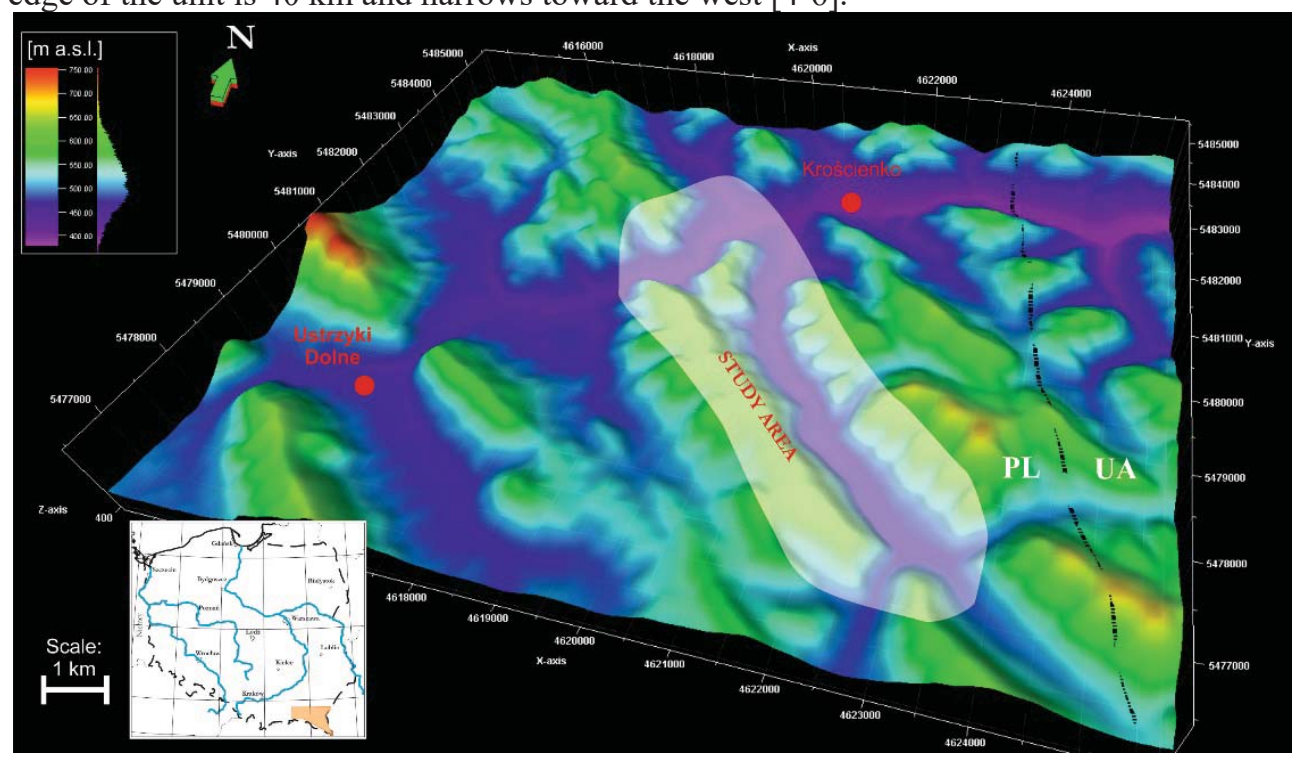

Fig. 1. Study area location.

\subsection{Methodology}

30 samples of the Inoceramian sandstones of the Skole Unit, as part of the Outer Carpathians, were investigated. The permeability was measured on the basis of the known Swanson model based on the threshold pore diameter. Parameter measurements of pore space of sandstone rock samples will be taken by AutoPore II 9220 firm Micromeritics (Fig. 2). The apparatus used for this process control computer injection of mercury from a pressure less than ambient to $413.4 \mathrm{MPa}$, allowing penetration of pores or fractures with a diameter or aperture of $0.003 \mu \mathrm{m}$ to $360 \mu \mathrm{m}$. These tests are based on a cylindrical pore space model, in which the pore space is treated as a bundle of cylindrical capillaries conductive fluid reservoir. 
Based on the results of porosimetry measurements were determined the following values, characterized pore space geometry of analyzed sample [1].

The bulk density. Density relating to the total bulk volume of the sample. Bulk volume of the sample is determined by mercury pycnometer.

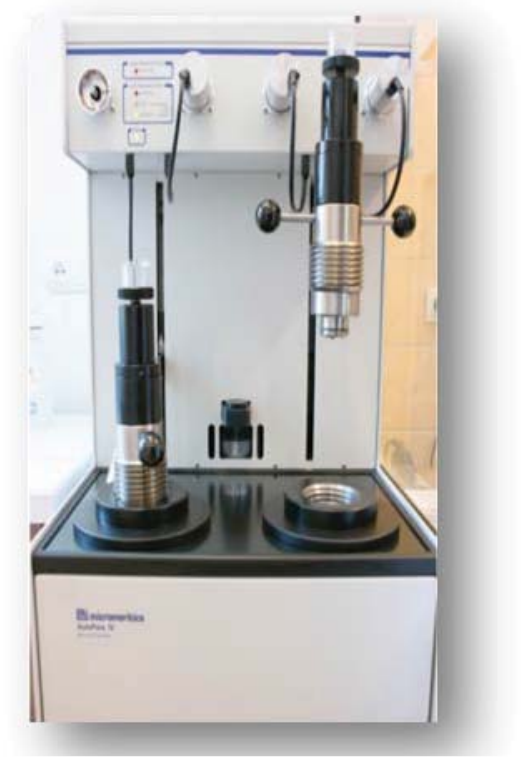

Fig. 2. Porosimeter AutoPore IV 9520 (Micromeritics) [7, modified].

Porosity count of the porosimetry. This porosity is different than the open porosity in that the count of nonwetting liquid volume which has been pressed into the sample. This volume does not include all the sub-micropores, whose diameter is too small for mercury penetration. This value will be so dynamic porosity. Porosity coefficient in porosimetry is calculated by dividing the total volume of mercury penetrated into the sample by the bulk volume:

where:

$$
\phi_{d}=\frac{V_{H g}}{V_{b}}
$$

$\phi_{d}$ - porosity coefficient [\%],

$V_{H g}$ - the total mercury volume penetrated into the sample $\left[\mathrm{cm}^{3}\right]$,

$V_{o b j}$ - the bulk volume of the reservoir rock $\left[\mathrm{cm}^{3}\right]$.

The average pore diameter used to assess the quality of the reservoir rock. This value is calculated as a weighted average of the pores weight, and not the percentage of pore space.

Percentage distribution of the pore diameter in the pore space is determined by counting the fractional volume of mercury penetrated to the sample. To determine the relationship pores - fractures is possible to determine the percentage of pores and fractures determining the possible hydrocarbon migration and accumulation.

The measurement consists of injecting mercury into the sample at the desired pressure and measuring the pressure and the volume of mercury which injected into a sample at this pressure. The cumulative curve is obtained according to the applied pressure - the volume of mercury. Knowing the sample weight and the setting during the porosimetric measurement its volume and a bulk volume of the rock skeleton by converting the results 
obtained Washburn formula gives the distribution of pore diameter in a given sample and a partial volume, the porosity of the sample, the skeletal density and apparent.

The total area of the pore space. This is the total pore surface area per unit volume (weight) of test rocks and a measure of the quantity of the resistance of the porous medium flowing fluid. It is calculated based on the cylindrical model of Washbourna [1]:

where:

$$
\sum \Delta A=\frac{\sum P_{c} \cdot V}{\sigma \cdot \cos \theta}
$$

$A$ - surface area $\left[\mathrm{m}^{2} / \mathrm{m}^{3}\right]$,

$\Delta V$ - partial volume corresponding to the pressure $P_{c}\left[\mathrm{~m}^{3}\right]$,

$\sigma-$ surface tension $[\mathrm{N} / \mathrm{m}]$,

$\theta$ - contact angle $\left[^{\circ}\right]$,

$P_{c}$ - capillary pressure $[\mathrm{Pa}]$.

The irreducible water content. It is the sum of the residual water content in the sample and the micropore volume of such small diameter in which mercury cannot penetrate. The value is associated with the coefficient of dynamic porosity.

\section{Results and discussion}

The values of mercury porosimetry properties were obtained for each of the core samples. It was measured: the compactness, pore intrusion volumes, pore surface areas, pore specific surface areas, average pore diameters, bulk and skeletal densities, effective porosities.

As a result of the research conducted by the authors, cumulative curves of effective porosity and distribution of pore geometry were obtained. Figure 3 shows the cumulative porosity curves for 30 samples taken from sandstone outcrops of the selected area. These curves consist of the image of heterogeneous rocks with a porous-fracture type reservoir rock space of the mono-modal character. The shape of the cumulative curves indicates that the highest effective porosity is found in samples BD4 and BD5. This is confirmed in the pore geometry distribution graph (Fig. 4), where the pore system for these samples is in the range of 0.07 to $0.16 \mu \mathrm{m}$. For the rest of the samples, the pore system is in the range of 0.03 to $0.05 \mu \mathrm{m}$ in diameter, indicating low effective porosity. Within the micropore range, single isolated peaks are visible in the geometry graph, which corresponds to microfractures with the aperture to several tenths of $\mu \mathrm{m}$.

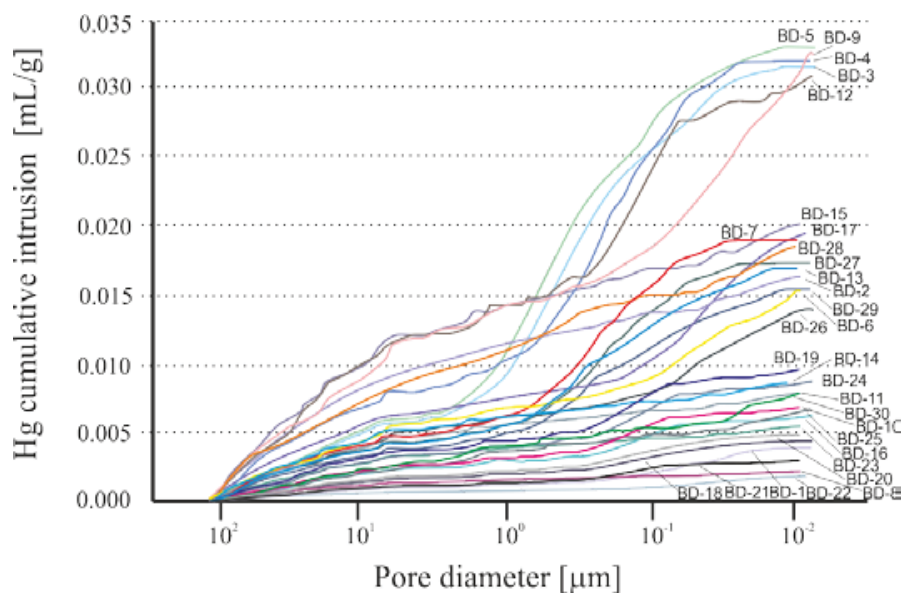

Fig. 3. The cumulative curves of the effective porosity. 


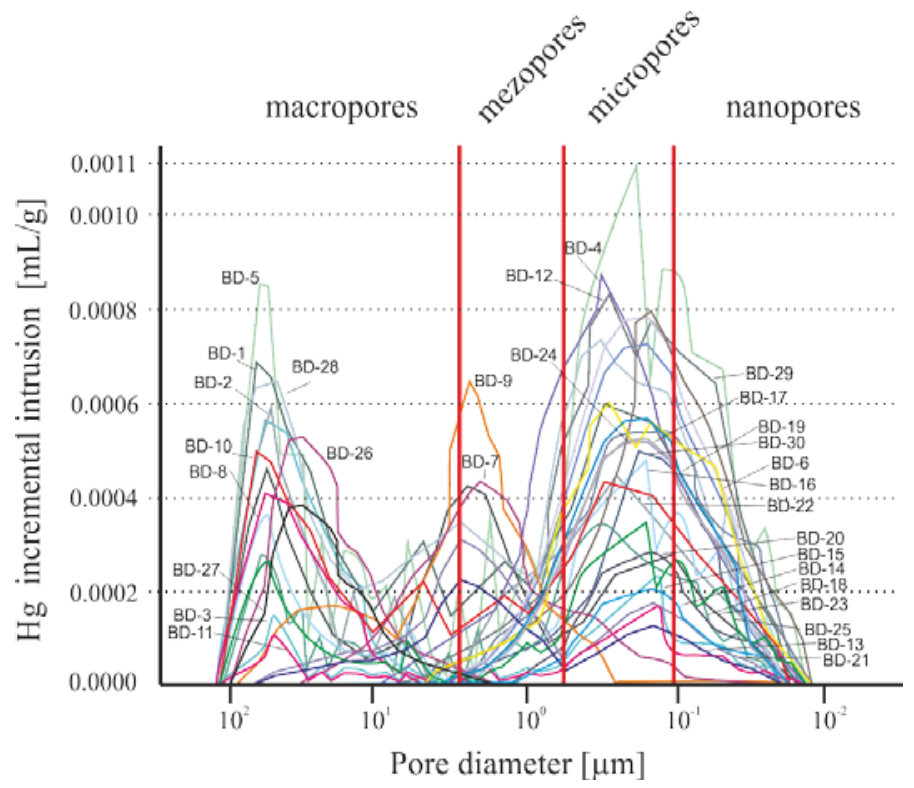

Fig.4 Pore geometry distribution.

It is worth adding that the cumulative curves of effective porosity of samples number BD3, BD4, BD5 flatten at the final fragment (Fig. 4), which shows that these samples are fully saturated with mercury at the applied pressure range. For the remaining samples, such flotation does not occur and indicates incomplete mercury saturation and the possibility of continuing the mercury loading process in the pores using a pressure higher than the maximum pressure that can be used. This indicates that in these samples there may be smaller pores out the measuring range of the porosimetry method. Looking still on the figure it is worth noting that the curves of cumulative effective porosity of samples are flattening in the final fragment which proves that sample is full saturated with mercury at applied pressure range and also indicates the reliability of data results. For other samples, such flattening does not exist and it proves incomplete saturation of its mercury to continuing the process of injecting mercury into the pores by applying a pressure higher than the maximum pressure, possible to use. This demonstrates that in these samples can occur pores far smaller, which are outside the measurement range of porosimetry method.

The juxtaposition of cumulative curves for samples indicates that the higher the mercury intrusion, and therefore a higher apparent porosity, due to the fact that in the porosimetry studies is greater availability of mercury into the pores of tested samples.

The results of the permeability were obtained using the Swanson model, which is based on the threshold diameter. The results indicated that the samples were characterized by low permeability values up to $0.00307 \mathrm{mD}$ for the „DB10” sample.

Based on literature data $[8,9]$ the ,tight" type reservoir rock have a permeability of $0.0001-0.1 \mathrm{mD}$, a close to the ,tight" type reservoir rock having a permeability of $0.1-1$ $\mathrm{mD}$ and a conventional reservoir rock of $1-1000 \mathrm{mD}$. The permeability analysis shows that most samples exhibit the characteristics of the ,tight” type reservoir rock.

Authors obtained the statistical description of the mercury porosimetry measured data. They are summarized in Figure 5 and Table 1. 

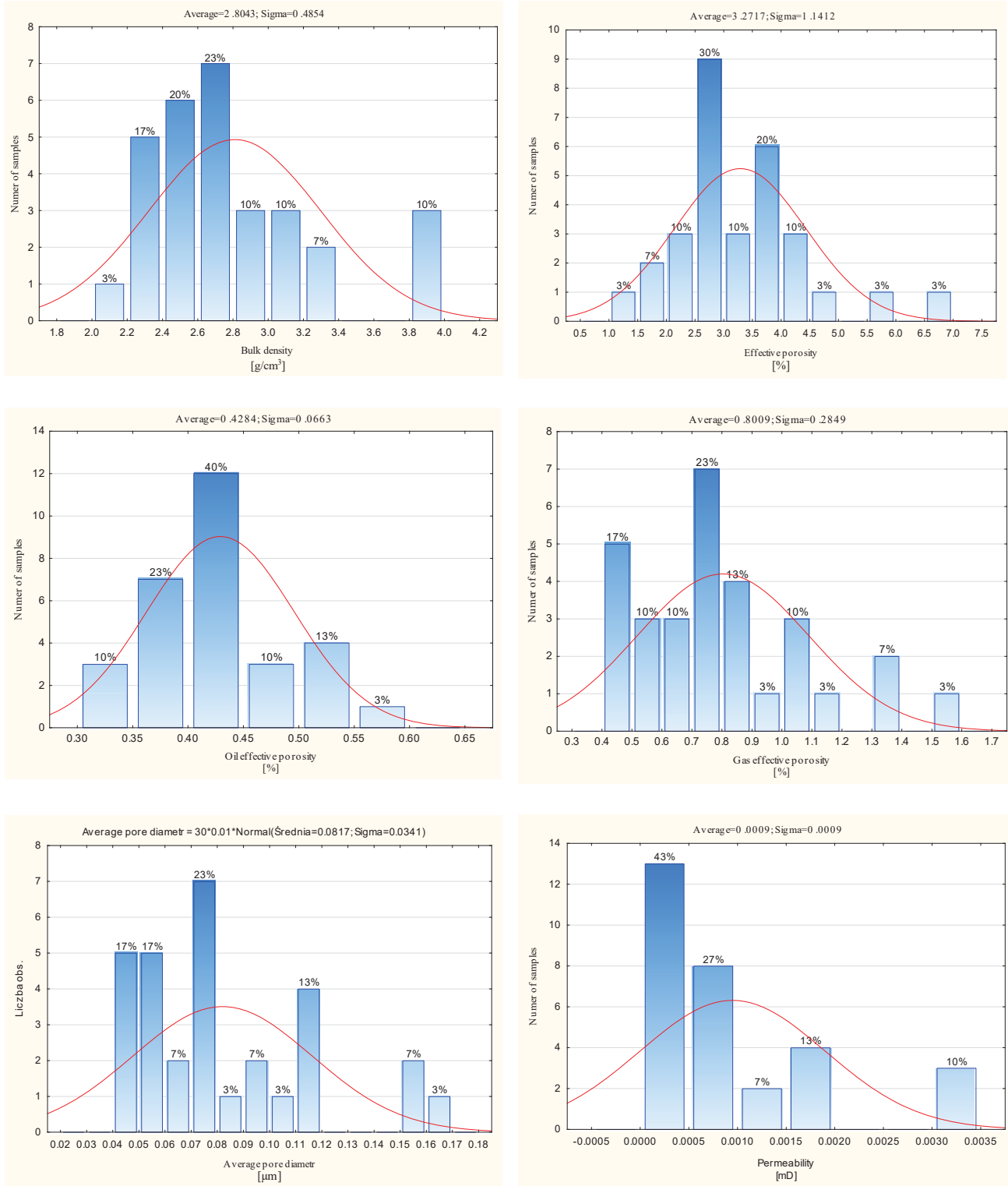

Fig. 5. Distribution of effective porosity.

Table 1. Statistical description of the mercury porosimetry measured data.

\begin{tabular}{|c|c|c|c|c|c|c|c|c|c|c|}
\hline & $\begin{array}{c}\text { Bulk } \\
\text { density }\end{array}$ & $\begin{array}{c}\text { Skeletal } \\
\text { density }\end{array}$ & $\begin{array}{c}\text { Total } \\
\text { intrusion } \\
\text { mercury } \\
\text { volume }\end{array}$ & Compactness & $\begin{array}{c}\text { Effective } \\
\text { porosity }\end{array}$ & $\begin{array}{c}\text { Oil } \\
\text { effective } \\
\text { porosity }\end{array}$ & $\begin{array}{c}\text { Gas } \\
\text { effective } \\
\text { porosity }\end{array}$ & $\begin{array}{c}\text { Average } \\
\text { pore } \\
\text { diameter }\end{array}$ & $\begin{array}{c}\text { Total } \\
\text { pore } \\
\text { area }\end{array}$ & Permeability \\
\cline { 2 - 11 } & {$[\mathrm{g} / \mathrm{cm} 3]$} & {$[\mathrm{g} / \mathrm{cm} 3]$} & $\mathrm{mL} / \mathrm{g}$ & {$[\%]$} & {$[\%]$} & {$[\%]$} & {$[\%]$} & {$[\mu \mathrm{m}]$} & {$[\mathrm{m} 2 / \mathrm{g}]$} & {$[\mathrm{mD}]$} \\
\hline $\operatorname{Min}$ & 2.10040 & 2.146254 & 0.005300 & 82.20105 & 1.36180 & 0.341 & 0.440 & 0.041 & 0.1840 & 0.0000110 \\
\hline $\operatorname{Max}$ & 3.94010 & 4.219400 & 0.017800 & 99.32500 & 6.61930 & 0.600 & 1.560 & 0.162 & 1.1980 & 0.0030700 \\
\hline Avg & 2.80427 & 2.927337 & 0.010836 & 92.11118 & 3.27166 & 0.428 & 0.801 & 0.082 & 0.6383 & 0.0009413 \\
\hline
\end{tabular}




\section{Conclusions}

The aim of the petrophysical studies using the porosimetric method was to identify the pore space structure of the sandstones of the selected area. This means that not only the porosity qualifies the rocks to potentially reservoir in a particular class, but also the other physical parameters of the space, as well as the size and distribution of the pore diameter, the fracture aperture, the surface area and the pore distribution geometry as a function of their diameter, in the range of overcapillary, capillary and subcapillary areas. Summarize on the basis of the preliminary analysis:

1. Inoceramian Sandstones of the study area are the reservoir rock of a pore-fracture type reservoir space of a mono-modal character.

2. Pore space consist of micropores, which is associated with the "tight" type rock.

3. The analysis showed low values of permeability and a variation in effective porosity $(1,3-6,6 \%)$

4. Presented petrophysical characteristic shows that the Inoceramian sandstones show features of unconventional reservoir rocks.

The presented results were considered preliminary, due to limited data. To confirm the results of the study, the authors plan to repeat the study using helium porosimetry in the next phase of the work.

\section{References}

1. P. Such, Prace naukowe INiG (in Polish), 183, 153 (2012)

2. F. Javadpour, D. Fisher, M. Unsworth, Journal of Canadian Petroleum Technology, 46, 10 (2007)

3. S.M. Aboujafar, EAGE Reservoir Characterization and Simulation Conference, 1-8 (2009)

4. P. Karnkowski, „Geos” AGH Kraków, 2 (1993)

5. J. Waraszyńska, Karpaty Polskie. Wydawnictwa Uniwersytetu Jagiellońskiego (1995)

6. E. Stupnicka, Geologia regionalna Polski, Wydawnictwa Uniwersytetu Warszawskiego (1997)

7. http://galaxy.agh.edu.pl/ k-se/x/pl/team/laboratorium-porozymetryczne/ access 18.06.2017

8. K. Słupczyński, R. Semyrka, E. Bobula, Polish Journal of Mineral Resources, Geosynoptics GEOS, Kraków, 3, 191-195 (2001)

9. P. Such, Prace naukowe INiG, 113, 1-84 (2002) 